\title{
1 When does it pay to cooperate? Strategic information exchange in 2 the harvest of common-pool fishery resources
}

4 Abstract

5 Harvesting common-pool fishery resources is often a competitive activity and important

6 questions remain about the costs and benefits of engaging in cooperative behavior. Here,

7 we link comprehensive data on fisher's information exchange networks and economic

8 productivity to test hypotheses about when it pays to cooperate by exchanging different

9 types of strategic information. We find that being well connected locally in information

10 exchange networks about both short-term topics (e.g., the location of species) and long-term

11 topics (e.g., technical innovations) is positively associated with productivity in both the short-

12 term (within fishing trips) and long-term (annually). In contrast, we find that exchanging both

13 types of information across distinct social divides - a form of brokerage - is negatively

14 associated with productivity. Our results therefore suggest that while there appears to be an economic benefit associated with cooperation across temporal scales in the harvest of common-pool fishery resources, exchanging strategic information across social divides may come at a cost - particularly under conditions of competition. We discuss our results in light of emerging research at the nexus of sociology and economics, providing key insight into the social-structural dynamics that help form the foundation for fisher decision-making and behavior.

Keywords: information exchange, cooperation, social network, fisher behavior, common-pool resources, fisheries 


\section{Introduction}

There is a large body of theoretical and empirical research that seeks to understand the conditions that facilitate cooperation in the harvest of common-pool resources. Classic economic theory would predict that individuals, acting as rational self-interested actors, would likely choose to defect from attempts at cooperative arrangements due to the nonexcludable and rivalrous nature of common-pool resources (Gordon, 1954; Hardin, 1968; Scott, 1955). Yet many argue this conceptualization is too simplistic, and under certain conditions common-pool resource users may choose to cooperate (Gintis, 2000; Ostrom, 1990); for example, when groups are small and coercion is possible (Olson, 1965), or when cooperation is reinforced by norms, ethical codes, and institutions (Ostrom, 2000).

Information exchange among marine fishers has long been a key focus of investigations into cooperation in common-pool resource settings (Evans and Weninger, 2014; Gatewood, 1984; Haynie et al., 2009; Pollnac and Carmo, 1980; Wilson, 1990). Fishers operate in a dynamic and complex ecological environment, often covering vast spatial scales across the open ocean where spatiotemporal dynamics can change in unpredictable ways (Wilson, 1990). Decision-making in this context can be further complicated by a complex array of socio-political and economic processes. For example, in the U.S. pelagic fishers operate under the jurisdiction of the U.S Magnuson-Stevens Act (NOAA, 2006), are subject to both U.S. environmental legislation and binding international conservation measures, and are governed by international fishery management organizations ${ }^{1}$, regional fishery management councils, and the U.S. National Marine Fisheries Service. Adding a further layer of complexity, all commercial fishers are faced with fluctuating fish prices, market competition, and the dynamics of supply and demand in deciding when and where to land their catch (Béné, 1996; Salas and Gaertner, 2004). Marine fisheries are thus characterized by repetitive and competitive interactions among individual fishers who must determine the most strategic use of inputs over time and space to transform wild stocks of fish into catch. Fishers need to make these critical decisions while accommodating their activities to complex and uncertain market dynamics, socio-political processes, and the spatiotemporal fluctuations of the open ocean.

To cope with this complexity, fishers may choose to cooperate by exchanging information with others to improve their decision-making (Salas and Gaertner 2004). Engaging in information exchanges can potentially reduce time and effort spent searching for fish aggregations (Branch et al., 2006; Gatewood, 1984), and facilitate the diffusion of technological innovations capable of enhancing vessel efficiency (Gezelius, 2007). However,

\footnotetext{
${ }^{1}$ Formally referred to as "Regional Fishery Management Organizations", though they are international in scope.
} 
68

decisions to engage in information exchange may be tempered by the competitive nature of fishing (Acheson, 1975; Gezelius, 2007; Wilson, 1990). Indeed, the rational actor model suggests that fishers acting in their own self-interest are unlikely to cooperate by participating in information exchanges because such exchanges can increase the efficiency of others (Gordon, 1954; Hardin, 1968; Scott, 1955). Yet existing empirical work in marine fisheries suggests that information transfer among fishers is widespread, though it does vary depending on the size, structure, and diversity of fishing communities, the biology of the fish involved, and the type and value of the information exchanged (Barnes-Mauthe et al., 2013; Branch et al., 2006; Gezelius, 2007; Wilson, 1990).

One of the most common arguments put forth is that fishers are more likely to cooperate by exchanging information with others when it is economically beneficial for them to do so (Haynie et al., 2009). Yet existing research that seeks to quantify the relationship between information exchange and economic gains in marine fisheries largely rely on simulations and other models that lack explicit data on patterns of information exchange in fishing communities (Dreyfus-Leon and Gaertner, 2006; Haynie et al., 2009; Millischer et al., 2006). ${ }^{2}$ When it actually pays for fishers to engage in cooperative information exchange behavior therefore remains an important empirical question. To this end, we employ comprehensive data on networks of information exchange, catch and effort, and economic cost-earnings among pelagic tuna fishers to contribute a better understanding of when it pays to cooperate in the harvest of common-pool fishery resources.

In line with the literature on the structural aspects of social capital (Borgatti et al., 2009; Burt, 2000; Lin, 1999), our empirical approach rests on the assumption that fishers' structural position in networks of fishery-related information exchange can affect their ability to access information that can improve their decision-making. The ability to access information flowing through networks of information exchange can be exceptionally critical when dealing with aggregated and highly migratory species such as schools of tuna (Salas and Gaertner, 2004). In this case, there are two types of information that can potentially influence fisher's productivity: (1) short-term information, such as information on the location of species that can influence fisher productivity within fishing trips, and (2) long-term information, such as information on technical innovations that can influence fisher productivity over a longer period of time (Barnes et al., 2016b; Gezelius, 2007; Mueller et al., 2008; Wilson, 1990). ${ }^{3}$

\footnotetext{
${ }^{2}$ One exception is Turner et al. (2014) who presented explicit information exchange network information on lobster fishers, yet was limited to analyzing perceived levels of fishing success rather than actual productivity. A final exception is Barnes et al. (2016b), which the analysis presented here builds on.

3 These definitions are in line with Gezelius (2007). Wilson (1990) refers to short-term vs. long-term information as "fine-grained" vs. "coarse-grained", while fishers studied in Muller et al. (2008) distinguished between "right now" and "after-hours" information, which was similar in scope to the categories identified here.
} 
To our knowledge there are no existing empirical studies examining the relationship between long-term information exchange and fisher economic outcomes, though existing research does provide insight into what we might expect regarding short-term information exchange. Specifically, fishers who work with others rather than alone and are prominently located within short-term information exchange networks (i.e., "network prominence", see Fig. 1) have been found to be more successful, particularly when targeting highly mobile species (Barnes et al., 2016b; Dreyfus-Leon and Gaertner, 2006; Mueller et al., 2008). Network prominence refers to how central or well-connected locally one is in a social network, which tends to be associated with increased access to information and resources (Borgatti et al., 1998; Freeman, 1979) and has been positively linked to economic productivity (Abbasi et al., 2011; Greve et al., 2010). By their very nature, information exchange networks comprise information channels that can reduce the amount of time and investment needed to gather and process information (Molina - Morales and Martínez - Fernández, 2009). They can also enable learning through close contact and intensive interaction, which can foster innovation (Conley and Udry, 2010; Rogers Everett, 1995). Well-connected, centrally located individuals in such networks thus tend to have increased opportunities to capitalize on these benefits while pursuing their goals. Building on this existing theoretical and empirical foundation, here we propose and test the following hypothesis:

H1: Being well connected locally (i.e., network prominence) in both short-term and long-term information exchange networks will be positively associated with productivity in both the short-run (within fishing trips) and long-run (annually).

Though we expect that in general, the ability to access both types of information can provide advantages that enable fishers to be more productive, there are important differences between the exchange of short-term and long-term information that require consideration. Most notably, short-term information can almost immediately, and visibly, increase fishing success, whereas the effects of long-term information are much less immediate and tangibly visible. For example, information on the location of high-value species can reduce search effort and increase high-value catch, thereby decreasing costs while increasing revenues. The time-scale at which this occurs is almost immediate, i.e., productivity is increased within fishing trips. Perhaps more importantly, fishers are highly aware of this (Gezelius, 2007), particularly when all vessels unload their catch at a central location. Short-term information in marine fisheries is therefore known to be highly guarded, often only exchanged within small groups of trusted individuals (Gezelius, 2007; Wilson, 1990). This reflects the competitive nature of fishing and the highly visible effects of short-term information on fisher productivity, which calls into question how fishers that bridge divides between groups in the 
134

135

136

137

138

139

140

141

142

143

144

145

146

147

148

149

150

151

152

153

154

155

156

157

158

159

160

161

162

163

164

165

166

167

168

structure of short-term information exchange networks may fare.

Crossing social divides can be considered a form of bridging or brokerage (see Fig. 1), which has strong support in the literature for producing competitive advantages that lead to economic gains (e.g., Abbasi et al., 2011; Burt, 1992; Burt, 2005; Tsai and Ghoshal, 1998). This is primarily because groups that are largely disconnected in social structures often possess heterogeneous knowledge and resources - thus, people who broker across these divides have the ability to gain access to, and control over diverse information and resources, thereby gaining a competitive advantage (Burt, 2005). However, recent research has highlighted the fact that there are inherent pressures associated with brokering roles that can place constraints on actors, and these constraints can actually have a negative effect on productivity (Bizzi, 2013; Krackhardt, 1999; Stovel and Shaw, 2012). For example, when social networks are clustered, and particularly in competitive environments, an "usthem" attitude can emerge (McPherson et al., 2001). Those who broker across distinct groups in such settings can face conflicting normative pressures. Others may also begin to question their loyalties and commitments, which can generate distrust from actors on both sides of the divide (Bailey, 1963; Stovel et al., 2011; Stovel and Shaw, 2012). Exploring this potential issue for the first time in an environmental system, Barnes et al. (2016b) recently found that fishers who bridge distinct social divides in short-term information exchange networks may actually face an economic penalty, i.e., they found that brokers generated significantly less revenue than your average fisher. In interpreting their findings, the authors suggest that because fishing is such a competitive activity, and because short-term information tends to only be exchanged within small groups of trusted individuals due to its ability to almost immediately and visibly affect productivity, brokers may be penalized for interacting across groups. Specifically, they suggest that critical information may be withheld from brokers, who might be seen as breaking normative rules of information exchange by cooperating with "the competition".

To our knowledge, there have been no empirical studies of the effects of long-term information exchange on fisher productivity. Though long-term information, such as technical knowledge on gear innovations, can similarly increase fishing success, the time-scale at which this occurs is typically longer, i.e., efficiency gains are typically realized over the course of multiple fishing trips, each of which can independently span several weeks. Perhaps more importantly, the effects of long-term information are less obvious. This helps to explain why long-term information is thought to be exchanged much more openly among fishers and across fishing communities than short-term information (Gezelius, 2007; Wilson, 1990). Existing research also suggest that fishers may be more open to exchanging 
169

170

171

172

173

174

175

176

177

178

179

180

181

182

183

184

185

186

187

188

189

190

191

192

193

194

195

196

197

198

199

200

201

technical and other long-term information because it can afford them with prestige by providing an opportunity to demonstrate a technical advantage (Gezelius, 2007). Thus, in addition to our expectation that being prominently located in long-term information exchange networks will be beneficial, we expect that the classically positive effects of brokerage are also likely to be realized. Specifically, we propose and test the following specific hypothesis:

H2: Brokering between distinct social divides (i.e., brokerage) in short-term information exchange networks will be negatively associated with productivity in the short-run (within fishing trips), yet brokering between social divides in long-term information exchange networks will be positively related with productivity in the long-run (annually).

In summary, we extend previous enquires into the effects of information exchange among fishers by leveraging explicit information exchange network data on both short-term and long-term topics among a population of fishers. Though we expect that cooperating by exchanging information will generally be associated with economic benefits via increased productivity to individual fishers, we hypothesize that these benefits will differ to some extent depending on the type of information exchanged: short-term vs. long-term, which are temporally tied to when we expect to see these effects on productivity.

The remainder of this paper is structured as follows. In section 2 we describe the context of our study system. Section 3 provides a detailed description of our data, methodological approach, and empirical model. In section 4 we present our results. In section 5 we discuss our results and the limitations of the data, and conclude with implications for fisheries management and recommendations for future research.

\section{Study System: Hawaii's Longline Fishery}

Hawaii's pelagic longline fishery (Fig. 2) is a multimillion-dollar industry that supplies local and international markets with fresh tuna, swordfish, and other pelagic fish. In 2012 there were 129 active vessels that generated approximately USD \$94 million in revenue over the course of 19,424 fishing sets on 1,437 trips (see:

http://www.pifsc.noaa.gov/fmb/reports.php). Tuna, primarily bigeye (Thunnus obesus) is targeted with continuous mainlines that hang 2,000 - 3,000 baited hooks on dropping intervals strung between a procession of floats at depths of approximately $40-400$ meters over a range of 25 - 45 nautical miles in the open ocean. A small portion of the fleet also targets swordfish (Xiphias gladius) for a portion of the year using shallow-set mainlines hanging approximately $700-1,000$ baited hooks at depths of approximately $30-90$ meters. 
202 Hawaii's longline fishers are restricted from fishing within 50 - 75 nautical miles of Hawaii's

203 coastline, and tend to fish both within and outside of the U.S. Exclusive Economic Zone

204 bordering the Hawaiian Islands and in both the western and central Pacific ocean and

205 eastern Pacific ocean.

206 Though Hawaii has a diverse multicultural background (Nordyke, 1989), the fishery is made 207 up of only three distinct ethnic groups: a group of Vietnamese-Americans, Euro-Americans, 208 and Korean-Americans; and communication among fishers is significantly more extensive 209 within ethnic groups than between groups (Barnes-Mauthe et al., 2013; Barnes-Mauthe et 210 al., 2014). In social network terms, this is an example of a homophily effect, i.e., "birds of a 211 feather flock together" (McPhersan et al. 2001). In this case, the homophily effect has a 212 substantial impact on the overall structure of fisher's information exchange networks, and 213 low levels of trust across groups have been documented (Barnes-Mauthe et al., 2013;

214 Barnes-Mauthe et al., 2014). ${ }^{4}$

216 3. Methods

\section{$217 \quad 3.1$ Data}

218 To assess the role of having access to different types of information on fisher productivity we

219 utilized data on fisher's information-exchange networks, annual and trip-level expenditures, 220 and fish sales. These data are described in turn.

\subsubsection{Information Exchange Networks}

222 Comprehensive data on information exchange among more than $90 \%$ of all Hawaii longline 223 fishers $(n=143)^{5}$ was collected via a structured survey by Barnes-Mauthe et al. (2013) between May 2011 - January 2012. By fishers, we mean vessel owners and operators, which include both hired captains and owners who also operate their vessel, i.e., 'owneroperators'. In the survey, respondents were asked to identify up to 10 individuals they commonly exchanged useful information with regarding different aspects of fishing. Thus, the relationships identified represent respondent's perceptions of two-way information sharing ties. Though it could be argued that asking fishers to separately identify people they gave useful information to and people they got useful information from would have been more fruitful for identifying information access advantages, doing so would have doubled the

\footnotetext{
${ }^{4}$ Existing quantitative and qualitative research strongly suggests that ethnicity plays the dominant role in influencing the network homophily effect and the overall structure of Hawaii's longline fishery information exchange network over all other fisher attributes, such as age, title, education, and experience (Barnes-Mauthe et al., 2013).

${ }^{5}$ The original dataset included 145 respondents, two of which were dropped due to incomplete information.
} 
232 time it took fishers to complete the survey. Because Hawaii's longline fishers typically

233 operate year-round, only coming to port for an average of 1-4 days when unloading catch

234 and restocking before their next trip, such a substantial increase in respondent burden would

235 have dramatically reduced our sample size. In addition, discussions with key informants from

236 each ethnic group prior to conducting fieldwork suggested gauging what respondents

237 considered to be two-way information exchange relationships would be more likely to reduce

238 bias in the sample. This was due to the expectation that fishers would have been prone to

239 overestimating their importance for sharing useful information with others, while

240 underestimating the level at which they relied on others for useful information. In this case,

241 asking fishers to report who they exchanged information with was therefore selected as the

242 most appropriate approach.

243 After nominating individuals considered useful for information exchange, respondents were

244 asked to disclose which topic(s) were discussed with each individual from a predetermined

245 list. The topics included covered aspects of fishing that were determined through

246 discussions with key informants as important for decision making in either the short-run or

247 long-run, i.e., they could be considered either short-term or long-term topics. Short-term

248 topics included (1) fish activity (i.e., "what the fish are doing"), (2) site catch/set location

249 (where the fish are), (3) bycatch (which is preferably avoided while at sea), and (4) weather.

250 Long-term topics included (1) vessel technology, (2) hiring of captain or crew, (3) fishery

251 regulations, and (4) gear maintenance. Respondents often nominated other fishers as

252 important for information exchange, though some industry leaders ${ }^{6}$ and

253 government/management officials were also identified. The survey also collected basic

254 socio-demographic information from respondents, and was fielded in person with the help of

255 Vietnamese and Korean translators, as needed.

256 Using this data, we identified two different networks of information exchange. The first

257 network included ties used to exchange short-term information. Discussed in detail in the

258 following sections, we employ this network in our analysis of short-run, or trip-level

259 productivity for all vessel operators, including both hired captains and vessel owners who

260 also captain their vessel (owner-operators). The second network included ties used to

261 exchange long-term information. Discussed in detail in the following sections, we use this

262 network in our analysis of long-run, or annual productivity for all vessel owners (also

\footnotetext{
${ }^{6}$ The definition of "industry leader" was adopted from Barnes et al. (2013) who relied on key informants to define industry leaders as those whose role in the fishery included one or more of the following: (a) current or past representative on fishing association boards or fishery management councils relevant to Hawaii's longline fishery; (b) high-level, prominent employee or associate of a fishing organization, the Hawaii Fish Auction (where the majority of fish caught by Hawaii's longline fleet is landed), or other group that supports operations of Hawaii's longline fleet; (c) owner or high-level, prominent employee of supply stores that support Hawaii longline operations."
} 
263

264

265

266

267

268

269

270

271

272

273

274

275

276

277

278

279

280

281

282

283

284

285

286

287

288

289

290

291

292

293

294

295

296

including owner-operators). In this fishery less than $25 \%$ of the population both owns and operates their vessel; the remainder of vessel owners rely on hired captains (Barnes-Mauthe et al., 2013). The two networks are presented in Fig. 3.

\subsubsection{Annual and Trip-Level Expenditures}

In collaboration with NOAA's Pacific Islands Fisheries Science Center (PIFSC) Economics Program (see Kalberg and Pan, forthcoming), we collected information on vessel operating costs incurred during the 2012 calendar year from vessel owners and operators through the use of a structured survey. The survey focused primarily on annual fixed costs, and was fielded in person from January - September 2013 with the help of Vietnamese and Korean translators.

All trips targeting swordfish and $20 \%$ of trips targeting tuna that originate in Hawaii are federally mandated to carry an onboard fishery observer that collects detailed data on catch and effort. Through a joint effort between the PIFSC Economics Program and the Pacific Islands Regional Office (PIRO) Observer Program (Pan et al., 2014), vessel operators of all federally observed trips are also asked to voluntarily provide trip-level variable costs. Triplevel expenditures were voluntarily provided through this mechanism on $60 \%$ of all observed trips in 2012. Using this sample, we developed a regression model to estimate a trip cost function accounting for individual vessel and trip characteristics; such as vessel length, number of fishing sets, trip length, and travel distance; in order to generate cost information for all trips for which we did not have expenditure information. In the example of fuel cost estimation for a particular trip, the fuel usage is estimated based on its trip length (days), travel distance (miles), vessel size (feet), and a dummy variable to represent an individual vessel's unobservable heterogeneity (see Kalberg and Pan, forthcoming).

\subsubsection{Fish Sales}

The Hawaii Department of Aquatic Resources maintains detailed records of fish purchased from Hawaii's longline fleet by Hawaii marine fish dealers, including information on number of fish bought by species, price per pound paid, and weight and value of each fish. By linking these dealer reports with fisher's federally mandated logbook records we directly acquired revenue data for all longline trips that landed their catch in Hawaii in 2012. There were also a handful of Hawaii-based trips that landed their catch outside of Hawaii in 2012, resulting in a record of catch and effort present in logbooks, but not accounted for in the dealer reports. As a proxy revenue for these trips, the average weekly fish prices and average weight by species from the dealer data were multiplied by the number of kept fish by species as recorded in federal logbooks to estimate trip revenues. Weekly average prices and weights 
297 were used to mitigate the variation a single vessel might influence in daily averages, while

298 still maintaining the temporal variation in both price and weight per piece of fish kept (see

299 Kalberg and Pan, forthcoming). ${ }^{7}$

300

301

302

303

304

305

306

307

308

309

310

311

312

313

314

315

316

317

318

319

320

321

322

323

\subsubsection{Data Compilation}

We integrated all data on expenditures and sales using vessel permit numbers or vessel names and landing dates, trip return dates, and sales data. We used information on vessel ownership during the 2012 calendar year collected via the information exchange network survey to link vessel owners to their respective vessels. Vessel operators were linked to each fishing trip using a combination of fishery observer data that included operator names, and information from the network survey, where vessel operators reported all vessels they had operated within the last five years. In accordance with strict confidentiality agreements, the data was stripped of all names and other personally identifying information immediately after the data was merged.

\subsection{The Production Function Model}

Following similar approaches in the literature (e.g. Fafchamps and Minten, 2002), we incorporate information exchange proxies as added inputs in the production function in order to test the role of information exchange on fishers' economic productivity. The general production function can be written as,

$$
Y=F(L, K)
$$

where total production $Y$ is assumed to be a function of labor $L$ and capital $K$. Following Fafchamps and Minten (2002), in specifying a production function for Hawaii's longline fishers we can distinguish physical from human capital and include information exchange inputs as an additional factor of production. Consider a fishing vessel with economic outcome $Y$ (revenue), labor $L$ (crew size), capital or inputs $K$ (trip length, fixed costs, variable costs, and other inputs), human capital $H$ (education, experience), information exchange inputs I (network prominence, brokerage), and vessel and owner/operator specific characteristics $Z$ (vessel size, vessel age, target species, ethnicity, etc.). Equation 1 can therefore be re-specified as,

$$
Y=F(L, K, H, I, Z)
$$

\footnotetext{
${ }^{7}$ Average auction prices for the same species can vary significantly between vessels due to fishing grounds, fish handling practices, the average time between landings and sales. There can also be substantial variations in fish size due to spatial-temporal variations.
} 
324

325

326

327

328

329

330

331

Here, we are specifically interested in information exchange, I. If information exchange is irrelevant to fisher's productivity, I should have no effect on output when controlling for $L, K$, $H$, and $Z$. Yet we hypothesize that when accounting for the other factors of production, being well connected locally in information exchange networks, i.e., network prominence $I_{p}$, will have a positive effect on $Y$, while brokering between socialy distinct groups, $I_{b}$ will have a negative effect for vessel operators in the short-run, but a positive effect for vessel owners in the long-run. Our empirical model following the traditional log-log functional form is therefore specified as,

$$
\begin{aligned}
\ln (Y)=\beta_{0}+ & a_{1} \ln (L)+\sum_{n=1}^{N} a_{n} \ln \left(K_{n}\right)+\beta_{1} H_{e d}+\beta_{2} \ln \left(H_{\text {exp }}\right) \\
& +\beta_{3} \ln \left(I_{p}\right)+\beta_{4} \ln \left(I_{b}\right)+\sum_{n=1}^{N} \beta_{n} Z_{n}
\end{aligned}
$$

332

333

334

335

336

337

338

339

340

341

342

343

344

345

346

347

348

where $Y$ denotes gross revenue, $L$ represents crew size, $K$ corresponds to various capital inputs described in Table $1, H_{e d}$ is a dummy variable for education (some college or higher), $H_{\text {exp }}$ denotes years of fishing experience, $I$ are the same as described above, and $Z$ denotes various vessel and operator specific variables (see Table 1).

Described in both Pradhan et al. (2003) and Barnes et al (2016b), using gross revenue instead of a quantity as the output is not truly a production function. However, catches in Hawaii's longline fishery typically feature multiple species that receive different market prices (i.e., vessels operate as multi-product firms). The use of value as an output rather than aggregated quantity of fish landed is therefore standard practice. ${ }^{8}$

Using this empirical approach, we estimated two separate production functions: one for vessel owners assessing the role of information exchange about long-term topics at the annual level (the long-run), and one for vessel operators assessing the role of information exchange about short-term topics at the trip-level (the short-run). Because the network metrics used to capture information exchange can violate the assumption of independence central to standard statistical approaches, we applied a nonparametric bootstrap method to estimate robust standard errors following Banerjee et al. (2013). Both analyses correspond to the 2012 calendar year.

\subsection{Information Exchange Metrics}

\footnotetext{
${ }^{8}$ The value output is indicative of both quantity of production and the quality of the product. Tuna quality is largely a factor of trip length, fishing grounds and fish handling practices.
} 
350

351

352

353

354

355

356

357

358

359

360

361

362

363

364

365

366

367

368

369

370

371

372

373

374

375

376

377

378

379

380

381

382

383

To gauge information exchange, we employed structural measures of network prominence and brokerage using the information exchange networks described in section 3.1.1 (see

Table 1). To capture network prominence we used indegree centrality. Indegree centrality is a simple measure of local centrality that measures the number of incoming edges (i.e., ties) a node has in a network. We used indegree centrality rather than outdegree (ties going out from an actor) because we assume incoming ties more accurately represent fishers' ability to access information in this case due to an underlying level of trust associated with being nominated by others as someone they commonly exchange information with. Outdegree was also capped in our survey at a max of 10 , i.e., fishers were only asked to nominate up to 10 individuals. The variation of outdegree was thus limited to between 0 and 10 , which constrained its ability to identify truly well-connected fishers who had access to more than 10 information sources. By comparison, indegree ranged from 0 to 23 for vessel operators in the short-term information exchange network, and from 0 to 50 for vessel owners in the longterm information exchange network, suggesting that at least some fishers indeed have the ability to access information from more than 10 independent sources when needed.

We measured brokerage using both a structural and qualitative approach. Structural measures of brokerage capture bridging or brokering across groups that are structurally distinct in a social network, while qualitative measures capture bridging or brokering across socially heterogeneous groups (Borgatti et al., 1998). To capture structural brokerage across otherwise disconnected groups, we employed the measure network 'efficiency', which builds on Burt's (1992) theory of structural holes. In his discussion of structural holes, Burt (1992) was primarily interested in the number of opportunities for brokerage in a network. Building on this, the efficiency measure captures the suitability of a network for brokerage, given the number of opportunities, by idealizing non-redundant contacts. More formally, efficiency calculates the number of disjoint groups an actor is connected to divided by their total number of contacts, where disjoint groups are those that are otherwise not connected. ${ }^{9}$ Due to the strong social divides along ethnic lines present in Hawaii's longline fishery (BarnesMauthe et al., 2013; Barnes-Mauthe et al., 2014), we also conceptualized brokerage qualitatively as the total number of ties each actor had that spanned ethnic groups. This measure was inspired by existing work that argues ties that bridge heterogeneous subgroups in networks constitute an important form of brokerage (Borgatti et al., 1998; Stovel and Shaw, 2012), and was modeled after Barnes et al. (2016b).

We generated indegree centrality and brokerage metrics using two separate networks for vessel owners and operators (Fig. 3). For vessel owners, we used the long-term network

\footnotetext{
${ }^{9}$ Efficiency calculates the effective size of an actor's ego network divided by their degree centrality, where effective size equals degree centrality minus the average degree of alters (see Abbasi et al., 2014).
} 
384

385

386

387

388

389

390

391

392

393

394

395

396

397

398

399

400

401

402

403

404

405

406

407

408

409

410

411

412

413

414

415

416

described in section 3.1.1 which consisted of ties identified by all respondents as important for exchanging information about vessel technology, hiring captain or crew, gear maintenance, and fishing regulations. In the network survey, respondents were asked how valuable the information was that they exchanged with each person they nominated (very valuable, somewhat valuable, not valuable). Because we were interested in information that could, in theory, boost fisher productivity, ties deemed "not valuable" were dropped. The remaining information exchange network was treated as binary, i.e., it included all ties reported as very valuable or somewhat valuable by respondents. There were two sets of partner owners in our data who jointly shared multiple vessels. We treated partner owners as a single actor by merging their ties. Specifically, if a set of partners each identified a tie to the same person, we counted this as one outgoing tie for the partner pair. Likewise, if a different actor identified a tie to both individuals in the partner pair, we treated this as one incoming tie. The resulting network includes 167 nodes, 781 ties, has a mean geodesic distance of 4.17 , an average indegree of 4.73 ties, one weakly connected component containing all nodes, and a homophily index of -0.86 , where -1 indicates extreme ethnic homophily ${ }^{10}$ (Fig. 3). Of the 167 nodes, 153 were fishers. Of the remaining nodes, 10 were industry leaders not directly involved in fishing (i.e., they did not own a fishing vessel) and four represented government or management officials that respondents deemed important for information exchange.

For vessel operators, we used the short-term network described in section 3.1.1 which consisted of ties identified by all respondents as important for exchanging information about fish activity, site catch/set location, bycatch, and weather. As in the long-run network, ties identified as "not valuable" were dropped. The remaining information exchange network was treated as binary, i.e., it included all ties respondents reported as very valuable or somewhat valuable. The resulting network included 158 nodes, 620 ties, a mean geodesic distance of 4.12 , an average indegree of 3.92, one weakly connected component containing all nodes, and a homophily index of -0.88 (Fig. 3). Of the 158 nodes, 150 were fishers and eight were industry leaders deemed important by respondents for information exchange. With the exception of a single captain, everyone in the vessel operator short-term information exchange network appears in the vessel owner long-term information exchange network. In contrast, the vessel owner long-term information exchange network has seven owners, one captain, one owner-operator, six industry leaders, and six government or management officials who do not appear in the vessel operator short-term information exchange network.

\footnotetext{
${ }^{10}$ The homophily index is equal to the number of ties external to groups minus the number of ties internal to groups, divided by the total number of ties possible. This results in a value that ranges from +1 (in cases of extreme heterophily) to -1 (in cases of extreme homophily).
} 
418 Other inputs used in the production function are presented in Table 1. Explanatory variables

419 for vessel owner's annual-level production function differed slightly from that of vessel

420 operator's trip-level production function, primarily due to the difference in scale at which the

421 production process was estimated (see Tables 2 and 3). Specifically, vessel owner's

422 production functions were estimated at the annual level accounting for all trip days, inputs,

423 and total annual revenue, whereas operator's production functions were estimated at the trip

424 level accounting for trip days, average inputs, and average trip-level revenue. For vessel

425 owners, capital inputs were aggregated into fixed and variable costs, where the former

426 included costs associated with dry docking, engine work, gear added/replaced, and

427 continuous maintenance; and the latter included trip-level costs, such as fuel, bait, engine

428 oil, provisions, ice, fishing gear replacement, and communication. Only trip-level costs were

429 included in operator's production functions (denoted as other inputs, Table 1). Vessel and

430 operator specific variables are also included, one of which accounts for fishers that both own 431 and operate their vessel.

\section{$432 \quad 3.5$ Sample}

433 The compiled data described in Section 3.1.4 included information on 128 unique vessels, 43430 of which were associated with owners not present in the network dataset. Data on an 435 additional seven vessels were missing key productivity variables, resulting in a total usable 436 sample of 91 vessels associated with 87 owners to be used to estimate vessel owner's 437 annual-level production function. $15 \%$ of these vessels targeted swordfish for at least one 438 trip during the year, while the other 85\% targeted tuna only. Summary statistics for the 2012 439 annual-level data included in vessel owner's production function are presented in Table 2.

440 For vessel operator's trip-level production function, we first evaluated swordfish trips 441 separately from tuna trips because they consist of very different fishing profiles (i.e., different 442 depths, times, number of hooks, etc.). The trip-level data for 2012 included 984 recorded 443 tuna trips, 40 of which were taken by operators not present in the network data. An 444 additional 91 trips were missing key variables, resulting in a total usable sample of 853 tuna 445 trips taken by 84 vessel operators on 85 unique vessels during the 2012 calendar year. The 4462012 trip-level data also included a total of 54 recorded swordfish trips made by 14 unique 447 vessels. However, operators of these vessels were all Vietnamese-American, and there was 448 very little variation in their patterns of information exchange or vessel operating 449 characteristics. Our analysis on vessel operators therefore focuses on tuna targeting trips 450 only. Note that all vessel operators on swordfish trips also participated in tuna trips during 
451 the 2012 calendar year. Summary statistics for the trip-level data included in vessel

452 operator's production function are presented in Table 3.

453

\section{4. Results}

455 Our initial estimation of vessel owner's annual-level production function described in Eq. 3

456 exhibited problematic signs of collinearity among the information exchange metrics. ${ }^{11}$

457 Specifically, we found that inter-ethnic ties had a strong positive correlation with both

458 indegree centrality and efficiency for vessel owners in the long-term information exchange

459 network (Table 4). The same relationship was not present among vessel operators in the

460 short-term information exchange network (Table 4). We therefore had to exclude inter-ethnic

461 ties in the final long-run model for vessel owners, yet were able to retain it in the short-run

462 model for vessel operators, where there were no problematic signs of multicollinearity. ${ }^{12}$

463 Thus, in our analysis of the relationship between long-term information exchange and vessel

464 owner productivity, brokerage is restricted to the structural measure efficiency, and direct

465 inferences about the potential effect of the qualitative measure inter-ethnic ties cannot be

466 made. Final results for both production functions by ordinary least squares are presented in

467 Table 5.

468 In support of our first hypothesis, our results show that being well connected locally (i.e.,

469 indegree centrality) in both short and long-term information exchange networks has a

470 significant, positive relationship with productivity for both vessel operators at the trip-level

471 and vessel owners at the annual level. The effect is stronger for vessel owners $(\beta=0.085, p$

$472<0.05$ vs. $\beta=0.050, p<0.10$ ) but not statistically significant in terms of the difference.

473 Results regarding brokerage are partly at odds with our second hypothesis. We expected

474 bridging both structurally and socially distinct groups in the short-term information exchange

475 network to be negatively associated with productivity for vessel operators in the short-run,

476 and our results lend support to this hypothesis. However, we expected the opposite to be

477 true for vessel owners in the long-run, yet what we find instead is that structural brokerage

478 (efficiency) also has a significant, negative relationship with productivity for vessel owners in

479 the long-run (Table 5).

480 Results regarding other inputs are largely in accordance with expectations. All capital

481 variables have the expected sign, though only trip days and trip-level capital inputs are

482 significant (Table 5). Results regarding human capital are mixed, with experience playing a

\footnotetext{
11 The mean variance inflation factor (VIF) was 3.06, and VIFs for inter-ethnic ties and centrality were both $>3$.

12 The mean VIF is 2.14, and the VIF for all short-run information exchange metrics are $<1.5$.
} 
483

484

485

486

487

488

489

490

491

492

493

494

495

496

497

498

499

500

501

502

503

504

505

506

507

508

509

510

511

512

513

514

515

516

positive yet insignificant role, and education having a strong negative relationship with productivity in both the short-run and long-run. Fishers operating older vessels perform less well both in the short-run and long-run. Vessel size is also important, and in this case temporal scale matters. Specifically, medium sized vessels generate significantly more revenue on average than larger vessels in the short-run, yet having a larger vessel is positively associated with productivity in the long-run - though this relationship is not statistically significant. Our results also indicate that owners who switch between fishing for swordfish and tuna throughout the year are significantly less productive. Both owning and operating your vessel does not appear to play a significant role in influencing revenue in either case. Our results also indicate that when controlling for other variables, EuroAmerican fishers (both owners and operators) generate significantly more revenue than others.

\section{Discussion and Conclusion}

Our results offer evidence that engaging in strategic information exchange about both shortterm and long-term topics with close, localized contacts is positively related to economic productivity for commercial fishers (see results on network prominence, Table 5). These findings extend the results of Barnes et al. (2016b) to account for long-term information exchange and add further empirical support to broader claims on the value of cooperation in the harvest of common-pool fishery resources (Dreyfus-Leon and Gaertner, 2006; Millischer et al., 2006; Mueller et al., 2008; Turner et al., 2014; Wilson, 1990). Though a direct positive association between social interaction and performance has also been documented in other fields (e.g., Tsai and Ghoshal, 1998), to our knowledge no existing study has jointly examined this association in relation to both short-run and long-run performance in the same setting.

The message here appears relatively simple - the more direct contacts fishers have access to that they can leverage strategic information from on both short-term and long-term topics when needed, the better they perform in harvesting target species. This relationship holds in both the short-run (i.e., within fishing trips) and long-run. However, it's important to note that there is likely a limit to the positive relationship between the number of information exchange contacts that fishers have direct access to and higher returns because of saturation: as the number of information exchange contacts among fishers increases, the information exchange network as a whole becomes hyperconnected, likely resulting in information being redundant, rather than novel (Bodin and Crona, 2009). Another important caveat is that 
517 fishery resources are rivalrous in nature, and Hawaii's longline fishers operate under a total

518 allowable catch on bigeye tuna that applies to the entire fishery. This implies that if

519 maximizing centrality in information exchange networks has a direct casual relationship with

520 productivity, it's unlikely that this relationship would hold as more fishers sought to maximize

521 their centrality. This is due to the simple fact that there's a limit to how much can be caught.

522 In contrast to our results regarding strategic information exchange with close, localized

523 contacts, we found that engaging in information exchange across structurally or socially

524 distinct divides (brokering) may come at a cost. The most interesting result is that when it

525 comes to bridging structural divides, the type of information exchange does not seem to

526 matter - brokering has a negative association with productivity whether the information

527 exchanged is about long-term topics such as technological innovations, or short-term topics

528 thought to be more highly guarded, such as the location of fish aggregations. This stands in

529 contrast to dominant theories regarding brokerage that argue for its ability to provide tangible

530 economic benefits (e.g., Abbasi et al., 2011; Burt, 1992; Burt, 2005; Tsai and Ghoshal,

531 1998), and is somewhat puzzling considering existing research in fisheries examining

532 cooperative information exchange behaviors. For example, Mueller et al. (2008) found that

533 highly successful fishers in the Great Lakes area generally exchanged fishing related

534 information more frequently and with more individuals both within and outside their

535 subgroup $^{13}$ than less successful fishers. They also found that information exchanges

536 between subgroups (i.e., brokerage exchanges), tended to be more reliable than within,

537 which implies brokerage would likely have been even more important for fisher success in

538 their case. Moreover, long-term information is thought to be much more commonly

539 exchanged across fishing communities than short-term information (Gezelius, 2007; Wilson,

540 1990). Indeed, even in our case we found a higher level of ties crossing both social and

541 structural divides in the long-term information exchange network than in the short-term

542 information exchange network (Tables 2 and 3). Intuitively, one would expect that fishers

543 perceive a benefit from these brokerage relationships, yet our results clearly indicate they

544 are associated with a measurable economic disadvantage.

545 Though our findings regarding brokerage were somewhat unexpected and diverge from

546 dominant theories (i.e., Burt, 1992), the overwhelming majority of existing empirical work on

547 brokerage has been conducted in corporate and organizational settings comprised of

548 socially homogenous populations, and contrary evidence in more diverse environments has

549 been emerging. For example, Xiao and Tsui (2007) found evidence that the benefits of

550 brokerage typically found in more individualistic cultures can actually be reversed in cultures

\footnotetext{
${ }^{13}$ Subgroup is a network term used to describe individuals that are more densely connected to eachother than others in the network, thus, exchanges between them is a form of brokerage.
} 
551 where working collectively is considered important. The potential drawbacks of brokerage

552 have also been highlighted by Bizzi (2013), who showed that group composition can

553 sometimes constrain individuals, having a negative impact on their performance. Additional

554 research in sociology provides even further insight into our puzzling result, particularly when

555 considering the competitive nature of fisheries. In line with identity theory (Tajfel and Turner,

556 1979) and role conflict (Goffman, 1959), diverse settings characterized by strong homophily

557 and fragmentation can result in strong group identities. In cases where strong (and

558 potentially conflicting) social identities exist, which can be related to cultural background or

559 other, more subtle distinctions, the behavior of individuals is often heavily influenced by peer

560 pressure and normative expectations (Krackhardt, 1999). Sometimes these identities cause

561 individuals to emphasize their differences with others, which can decrease trust, amplify

562 conflict (Baerveldt et al. 2004), and result in discriminatory behavior across groups (Tajfel

563 and Turner, 1979) - particularly under conditions of competition (Poteete and Ostrom,

564 2004). Thus, in certain contexts brokering can be more tenuous and constraining for

565 individuals (Bizzi, 2013; Stovel et al., 2011), making it more difficult for them to realize the

566 information access advantages that are typically associated with bridging across distinct

567 social groups (Podolny and Baron, 1997). Indeed, recent research suggests that in complex,

568 dynamic environments, brokering between disparate parts of a social network can result in

569 disadvantaged access to information (Aral and Van Alstyne, 2011). It is well recognized that

570 marine fisheries constitute complex, dynamic systems (Jentoft, 2007; Levin and Lubchenco,

571 2008; Wilson, 1990), and our results suggest that when this is coupled with competition,

572 exchanging strategic information across distinct social divides is associated with a

573 demonstrable economic cost.

574 In the case of Hawaii's longline fishery, it's possible there exists a common suspicion of

575 fishers interacting across strong social divides driven by a lack of trust, which can result in

576 brokers being penalized by other fishers (Barnes et al., 2016b). For example, specific

577 strategic information that could knowingly increase fishing efficiency may simply be withheld

578 from brokers. A general sentiment of mistrust across distinct groups, particularly ethnic

579 groups, in this fishery has indeed been repeatedly observed by field researchers, leading to

580 it being characterized as ethnically fragmented despite the ties that exist across groups

581 (Barnes et al., 2016b; Barnes-Mauthe et al., 2013; Barnes-Mauthe et al., 2014). Ethnic

582 fragmentation has been shown to negatively impact trust, cooperation, and the provision of

583 public goods (Alesina et al., 2014; Alesina and La Ferrara, 2002; Chakravarty and Fonseca,

584 2014; Pomeroy et al., 2007), though histories and other factors can mediate these

585 relationships (Varughese and Ostrom, 2001). 
586 Our results leave us with a lingering question: if brokers are experiencing an economic 587 disadvantage for bridging distinct social divides, then why do they broker? Aside from the 588 simple explanation that fishers may be unaware of the economic disadvantage associated 589 with brokerage, it's possible that brokering provides fishers with other, non-monetary 590 rewards, such as benefits to their reputation and standing in the community (Gezelius, 591 2007). We suspect this might especially be the case for vessel owners exchanging 592 information about fishery management, technological innovations, and other long-term 593 topics, as previous accounts of fishers in other settings suggest engaging in this sort of 594 information exchange is thought to increase social prestige (Gezelius, 2007). Still, whether 595 brokerage provides non-monetary benefits of value to fishers remains an open question that 596 could be investigated in future research. The cross-sectional nature of our information 597 exchange network data also prevented us from investigating how stable these brokerage 598 relationships are. Considering brokerage is critical to achieve cooperation and collaboration 599 across stakeholder communities, which has been linked with improved management of 600 common-pool resources (Gruber, 2010; Nkhata et al., 2008; Ostrom, 1990), understanding 601 how brokerage affects individuals and learning how to stabilize brokerage are key (Stovel et 602 al., 2011), and could form the foundation for a fruitful future research agenda.

603 Our results are subject to some limitations, particularly the potential for endogeneity in our 604 empirical models. One possible issue is that more successful fishers may have abilities, 605 expertise, and other idiosyncratic features that set them apart from others that may also be 606 related to their position in the information exchange networks. Acknowledging this possibility, 607 we took several steps to minimize potential endogeneity. First, we asked fishers to 608 specifically identify people with whom they exchanged useful information about fishing, 609 rather than using second-hand data on formal group associations or spatial data on vessel 610 movements assumed to represent cooperation. Second, we included a number of individual611 level covariates (e.g., experience, education, owning and operating a vessel) that we know 612 are important for explaining fisher productivity and individual level network characteristics in 613 Hawaii's longline fishery, such as prominence and brokerage (see Barnes-Mauthe et al., 614 2014; Pradhan et al., 2003).

615 Still, there is the possibility of reverse causality. Instead of being centrally located in 616 networks of information exchange improving fisher productivity, it may be the case that 617 successful fishers are sought out more so than others for their skills and knowledge, driving 618 the positive association between productivity and network prominence. Likewise, our finding 619 of fisher's productivity being negatively associated with brokerage could be due to less 620 productive fishers seeking out other fishers outside their ethnic group to compensate for 
621 their lower ability. Furthermore, the possibility of 'fluidness' of network positions sets forth

622 complicated dynamic relationships between productivity and networks of information

623 exchange (Reagans and Zuckerman, 2008). Our cross-sectional empirical strategy

624 substantiates the association between these two factors but does not allow us to identify the

625 direction of causality. Thus, our estimates of the effects of information exchange may be

626 biased upwards and qualified as an upper-bound estimate. Nevertheless, our results provide

627 support for a positive association between productivity and being well connected locally in

628 networks of information exchange, and our counterintuitive finding regarding brokerage

629 suggests that at the very least, it does not improve fisher productivity. Future work should

630 build on our approach by identifying appropriate instrumental variables (see Wooldridge,

6312010 ) or by leveraging dynamic network data to account for network formation processes

632 and exploit lagged outcomes to firmly establish causal relationships.

633 In spite of these limitations, this research fills a critical gap in the literature regarding the costs and benefits of cooperation in the harvest of common-pool fishery resources. By explicitly investigating the relationship between strategic information exchange and fisher productivity, our results shed light on social-structural dynamics that help form the foundation for fisher decision-making and behavior. The social dynamics underpinning fisher behavior and decision-making have received very little attention in the literature compared to fish ecology and fish stock dynamics, yet understanding these dynamics is critical for devising effective fisheries management strategies that meet societal goals (Barnes et al., 2016a; Branch et al., 2006; Hicks et al., 2016) and avoid widespread fisheries collapse (Hilborn, 1985). Here, we demonstrated that while there is clearly an economic benefit associated with cooperation across temporal scales in the harvest of common-pool fishery resources, engaging in strategic information exchange across social divides is associated with a clear economic disadvantage. More fully understanding these relationships, why some fishers still choose to broker, and the stability of brokerage over time and in the face of external shocks should be the focus of future research.

\section{References}

650

651

652

653

654

655

656

657

658
Abbasi, A., Altmann, J., Hossain, L., 2011. Identifying the effects of co-authorship networks on the performance of scholars: A correlation and regression analysis of performance measures and social network analysis measures. Journal of Informetrics 5, 594-607.

Abbasi, A., Wigand, R.T., Hossain, L., 2014. Measuring social capital through network analysis and its influence on individual performance. Library \& Information Science Research 36, 66-73.

Acheson, J.M., 1975. The lobster fiefs: economic and ecological effects of territoriality in the Maine lobster industry. Human Ecology 3, 183-207. 
Alesina, A., Gennaioli, C., Lovo, S., 2014. Public goods and ethnic diversity: Evidence from deforestation in Indonesia. NBER Working Paper No. 20504, National Bureau of Economic Research.

Alesina, A., La Ferrara, E., 2002. Who trusts others? Journal of Public Economics 85, 207234.

Aral, S., Van Alstyne, M., 2011. The diversity-bandwidth trade-off1. American Journal of Sociology 117, 90-171.

Bailey, F.G., 1963. Politics and society in contemporary Orissa, in: Phillips, C.H. (Ed.), Studies on Modern Asia and Africa: Politics and Society in India. Allen \& Unwin, London, UK.

Banerjee, A., Chandrasekhar, A.G., Duflo, E., Jackson, M.O., 2013. The diffusion of microfinance. Science 341.

Barnes, M., Lynham, J., Kalberg, K., Leung, P.S., 2016a. Social networks and environmental outcomes. Proceedings of the National Academy of Sciences In press.

Barnes, M.L., Kalberg, K., Pan, M., Leung, P., 2016b. When is brokerage negatively associated with economic benefits? Ethnic diversity, competition, and common-pool resources. Social Networks 45, 55-65.

Barnes-Mauthe, M., Arita, S., Allen, S.D., Gray, S.A., Leung, P.S., 2013. The influence of ethnic diversity on social network structure in a common-pool resource system: Implications for collaborative management. Ecology and Society 18, 23.

Barnes-Mauthe, M., Gray, S.A., Arita, S., Lynham, J., Leung, P., 2014. What determines social capital in a social-ecological system? Insights from a network perspective. Environmental Management 55, 392-410.

Béné, C., 1996. Effects of market constraints, the remuneration system, and resource dynamics on the spatial distribution of fishing effort. Canadian Journal of Fisheries and Aquatic Sciences 53, 563-571.

Bizzi, L., 2013. The Dark Side of Structural Holes A Multilevel Investigation. Journal of Management 39, 1554-1578.

Bodin, Ö., Crona, B.I., 2009. The role of social networks in natural resource governance: What relational patterns make a difference? Global Environmental Change 19, 366374.

Borgatti, S.P., 2002. NetDraw: Graph Visualization Software. Harvard: Analytic Technologies, Lexington, Kentucy, USA.

Borgatti, S.P., Jones, C., Everett, M.G., 1998. Network measures of social capital. Connections 21, 27-36.

Borgatti, S.P., Mehra, A., Brass, D.J., Labianca, G., 2009. Network analysis in the social sciences. Science 323, 892-895.

Branch, T.A., Hilborn, R., Haynie, A.C., Fay, G., Flynn, L., Griffiths, J., Marshall, K.N., Randall, J.K., Scheuerell, J.M., Ward, E.J., 2006. Fleet dynamics and fishermen behavior: Lessons for fisheries managers. Canadian Journal of Fisheries and Aquatic Sciences 63, 1647-1668.

Burt, R.S., 1992. Structural Holes: The Social Structure of Competition. Harvard University Press, Cambridge, MA, USA.

Burt, R.S., 2000. The network structure of social capital. Research in Organizational Behavior 22, 345-423.

Burt, R.S., 2005. Brokerage and Closure: An Introduction to Social Capital. Oxford University Press, New York, NY, USA

Chakravarty, S., Fonseca, M.A., 2014. The effect of social fragmentation on public good provision: An experimental study. Journal of Behavioral and Experimental Economics 53, 1-9.

Conley, T.G., Udry, C.R., 2010. Learning about a new technology: Pineapple in Ghana. The American Economic Review 100, 35-69.

Dreyfus-Leon, M., Gaertner, D., 2006. Modeling performance and information exchange between fishing vessels with artificial neural networks. Ecological Modelling 195, 3036. 
714 Evans, K.S., Weninger, Q., 2014. Information sharing and cooperative search in fisheries.

Fafchamps, M., Minten, B., 2002. Returns to social network capital among traders. Oxford Economic Papers 54, 173-206.

Freeman, L.C., 1979. Centrality in social networks conceptual clarification. Social Networks $1,215-239$.

Gatewood, J.B., 1984. Cooperation, competition, and synergy: information-sharing groups among Southeast Alaskan salmon seiners. American Ethnologist, 350-370.

Gezelius, S.S., 2007. The social aspects of fishing effort. Human Ecology 35, 587-599.

Gintis, H., 2000. Beyond $<\mathrm{i}>\mathrm{Homo}$ economicus $</ \mathrm{i}>$ : evidence from experimental economics. Ecological Economics 35, 311-322.

Goffman, E., 1959. The presentation of self in everyday life, in: Newman, D.M., O'brien, J. (Eds.), Sociology: Exploring the Architecture of Everday Life Readings. Pine Forge Press, Thousand Oaks, CA, USA, pp. 120-129.

Gordon, H.S., 1954. The economic theory of a common-property resource: The fishery. The Journal of Political Economy 62, 124-142.

Greve, A., Benassi, M., Sti, A.D., 2010. Exploring the contributions of human and social capital to productivity. International Review of Sociology-Revue Internationale de Sociologie 20, 35-58.

Gruber, J.S., 2010. Key principles of community-based natural resource management: a synthesis and interpretation of identified effective approaches for managing the commons. Environmental management 45, 52-66.

Hardin, G., 1968. The tragedy of the commons. Science 162, 1243-1248.

Haynie, A.C., Hicks, R.L., Schnier, K.E., 2009. Common property, information, and cooperation: Commercial fishing in the Bering Sea. Ecological Economics 69, 406413.

Hicks, C.C., Levine, A., Agrawal, A., Basurto, X., Breslow, S.J., Carothers, C., Charnley, S., Coulthard, S., Dolsak, N., Donatuto, J., 2016. Engage key social concepts for sustainability. Science 352, 38-40.

Hilborn, R., 1985. Fleet dynamics and individual variation: why some people catch more fish than others. Canadian Journal of Fisheries and Aquatic Sciences 42, 2-13.

Jentoft, S., 2007. Limits of governability: Institutional implications for fisheries and coastal governance. Marine Policy 31, 360-370.

Kalberg, K., Pan, M., forthcoming. 2012 Economic Cost-Earnings of Pelagic Longline Fishing in Hawaii. Pacific Islands Fisheries Science Center, NOAA Technical Memorandum.

Krackhardt, D., 1999. The ties that torture: Simmelian tie analysis in organizations. Research in the Sociology of Organizations 16, 183-210.

Levin, S.A., Lubchenco, J., 2008. Resilience, robustness, and marine ecosystem-based management. BioScience 58, 27-32.

Lin, N., 1999. Building a network theory of social capital. Connections 22, 28-51.

McPherson, M., Smith-Lovin, L., Cook, J.M., 2001. Birds of a feather: Homophily in social networks. Annual Review of Sociology, 415-444.

Millischer, L., Gascuel, D., Drouineau, H., Mahévas, S., Pelletier, D., Beliaeff, B., TejerinaGarro, F.L., de Mérona, B., Oberdorff, T., Hugueny, B., 2006. Information transfer, behavior of vessels and fishing efficiency: an individual-based simulation approach. Aquatic Living Resources 19, 1-13.

Molina - Morales, F.X., Martínez - Fernández, M.T., 2009. Too much love in the neighborhood can hurt: how an excess of intensity and trust in relationships may produce negative effects on firms. Strategic Management Journal 30, 1013-1023.

Mueller, K.B., Taylor, W.W., Frank, K.A., Robertson, J.M., Grinold, D.L., 2008. Social networks and fisheries: The relationship between a charter fishing network, social capital, and catch dynamics. North American Journal of Fisheries Management 28, 447-462. 
Nkhata, A.B., Breen, C.M., Freimund, W.A., 2008. Resilient social relationships and collaboration in the management of social-ecological systems. Ecology and Society $13,2$.

NOAA, 2006. Magnuson-Stevens Fishery Conservation and Management Reauthorization Act of 2006, Public Law no. 109-479, 120 Stat 3575 (2006), Washington, D.C., USA. Nordyke, E.C., 1989. The Peopling of Hawai'i. University of Hawaii Press, Honolulu, HI. Olson, M., 1965. Logic of Collective Action: Public Goods and the Theory of Groups. Harvard University Press, Cambridge, MA, USA.

Ostrom, E., 1990. Governing the Commons: The Evolution of Institutions for Collective Action. Cambridge University Press, Cambridge, UK.

Ostrom, E., 2000. Collective action and the evolution of social norms. The Journal of Economic Perspectives 14, 137-158.

Pan, M., Chan, H., Kalberg, K., 2014. Tracking the Changes of Economic Performance Indicators for the Main Commercial Fisheries in the Western Pacific Areas 2012 Update. Pacific Islands Fisheries Science Center Internal Report (IR-14-017), Honolulu, HI, p. 18.

Podolny, J.M., Baron, J.N., 1997. Resources and relationships: Social networks and mobility in the workplace. American sociological review, 673-693.

Pollnac, R.B., Carmo, F., 1980. Attitudes toward cooperation among small-scale fishermen and farmers in the Azores. Anthropological Quarterly, 12-19.

Pomeroy, R., Parks, J., Pollnac, R., Campson, T., Genio, E., Marlessy, C., Holle, E., Pido, M., Nissapa, A., Boromthanarat, S., 2007. Fish wars: Conflict and collaboration in fisheries management in Southeast Asia. Marine Policy 31, 645-656.

Poteete, A.R., Ostrom, E., 2004. Heterogeneity, group size and collective action: The role of institutions in forest management. Development and Change 35, 435-461.

Pradhan, N.C., Sharma, K.R., Leung, P., 2003. Analyzing technical and economic interrelationships in Hawaii's longline fishery. Marine Resource Economics 18, 167194.

Rogers Everett, M., 1995. Diffusion of Innovations, 4th ed. The Free Press, New York, NY, USA.

Salas, S., Gaertner, D., 2004. The behavioural dynamics of fishers: Management implications. Fish and Fisheries 5, 153-167.

Scott, A., 1955. The fishery: The objectives of sole ownership. The Journal of Political Economy 63, 116-124.

Stovel, K., Golub, B., Milgrom, E.M.M., 2011. Stabilizing brokerage. Proceedings of the National Academy of Sciences 108, 21326-21332.

Stovel, K., Shaw, L., 2012. Brokerage. Annual Review of Sociology 38, 139-158.

Tajfel, H., Turner, J.C., 1979. An integrative theory of intergroup conflict, in: Austin, W.G., Worchel, S. (Eds.), The Social Psychology of Intergroup Relations. Brooks-Cale, Monterey, CA, USA, pp. 33-47.

Tsai, W., Ghoshal, S., 1998. Social capital and value creation: The role of intrafirm networks. Academy of Management Journal 41, 464-476.

Turner, R.A., Polunin, N.V.C., Stead, S.M., 2014. Social networks and fishers' behavior: Exploring the links between information flow and fishing success in the Northumberland lobster fishery. Ecology and Society 19.

Varughese, G., Ostrom, E., 2001. The contested role of heterogeneity in collective action: Some evidence from community forestry in Nepal. World Development 29, 747-766.

Wilson, J.A., 1990. Fishing for knowledge. Land Economics 66, 12-29.

Wooldridge, J.M., 2010. Econometric analysis of cross section and panel data. MIT press.

Xiao, Z., Tsui, A.S., 2007. When brokers may not work: The cultural contingency of social capital in Chinese high-tech firms. Administrative Science Quarterly 52, 1-31. 


\section{Fiqure Captions:}

825 Figure 1. An example of network prominence (A) and brokerage (B). Network prominence can be 826 captured by degree centrality, which corresponds to the number of direct ties one has in a network. In 827 network $A$, the node with the greatest number of ties (where degree centrality $=6$ ) is shaded in red.

828 Brokers act as intermediaries in networks by linking isolated individuals or disparate groups. In 829 network $B$, the blue shaded node is acting as a broker.

830 Figure 2. Map identifying the study area and the range of Hawaii's longline fleet, adapted from 831 Barnes et al. (2016b).

832 Figure 3. Graphical depictions of (A) vessel owner's information exchange network used to access 833 and share long-term information on vessel technology, hiring captain or crew, gear maintenance, and 834 fishing regulations; and (B) vessel operator's information exchange network used to access and share 835 short-term information on fish activity, site catch/set location, bycatch, and weather. By vessel owner, we mean all fishers who own a vessel. By vessel operator, we mean all fishers who operate their vessel, including both hired captains and owners who operate their vessel themselves (owner-

838 operators). Each shape or node represents an actor in the network, and the lines or edges connecting 839 them represent their information exchange ties. V-A, E-A, and K-A refer to each ethnic group

840 (Vietnamese-American, Euro-American, and Korean-American, respectively). The network was

841 created in NetDraw (Borgatti, 2002) using the spring embedding algorithm with node repulsion, which

842 uses iterative fitting to place nodes closest to those they have the shortest path lengths to while

843 minimizing overlap. 
A.
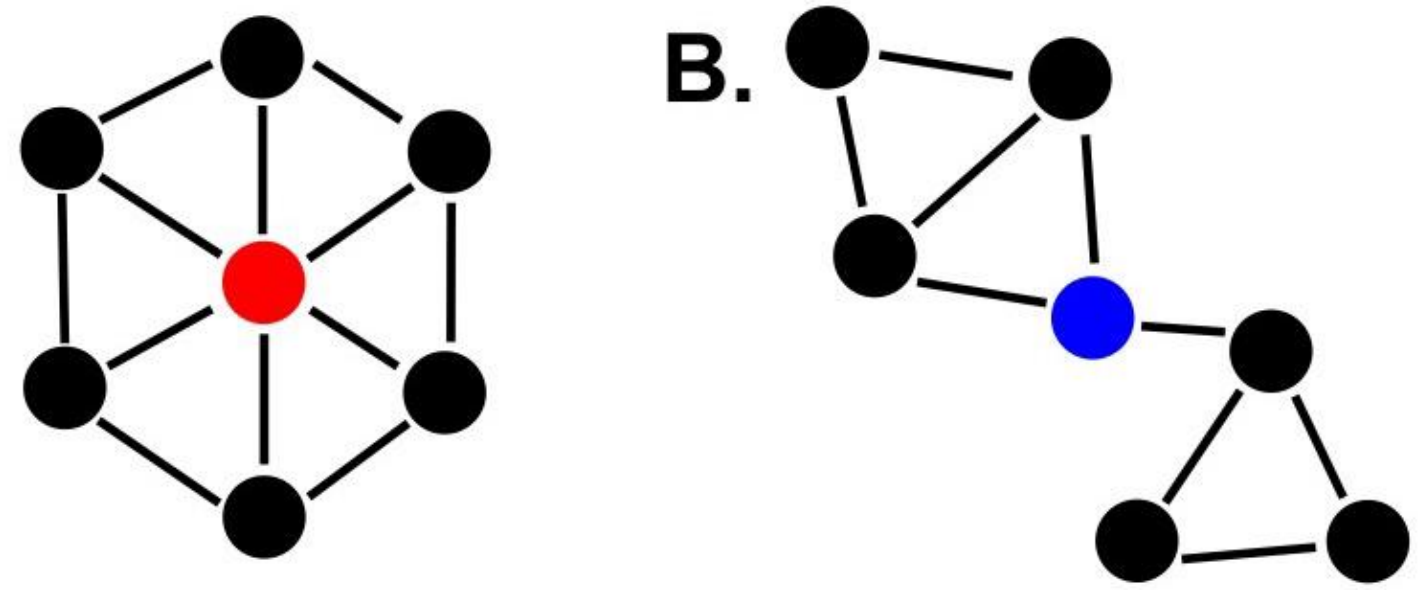

845

846 


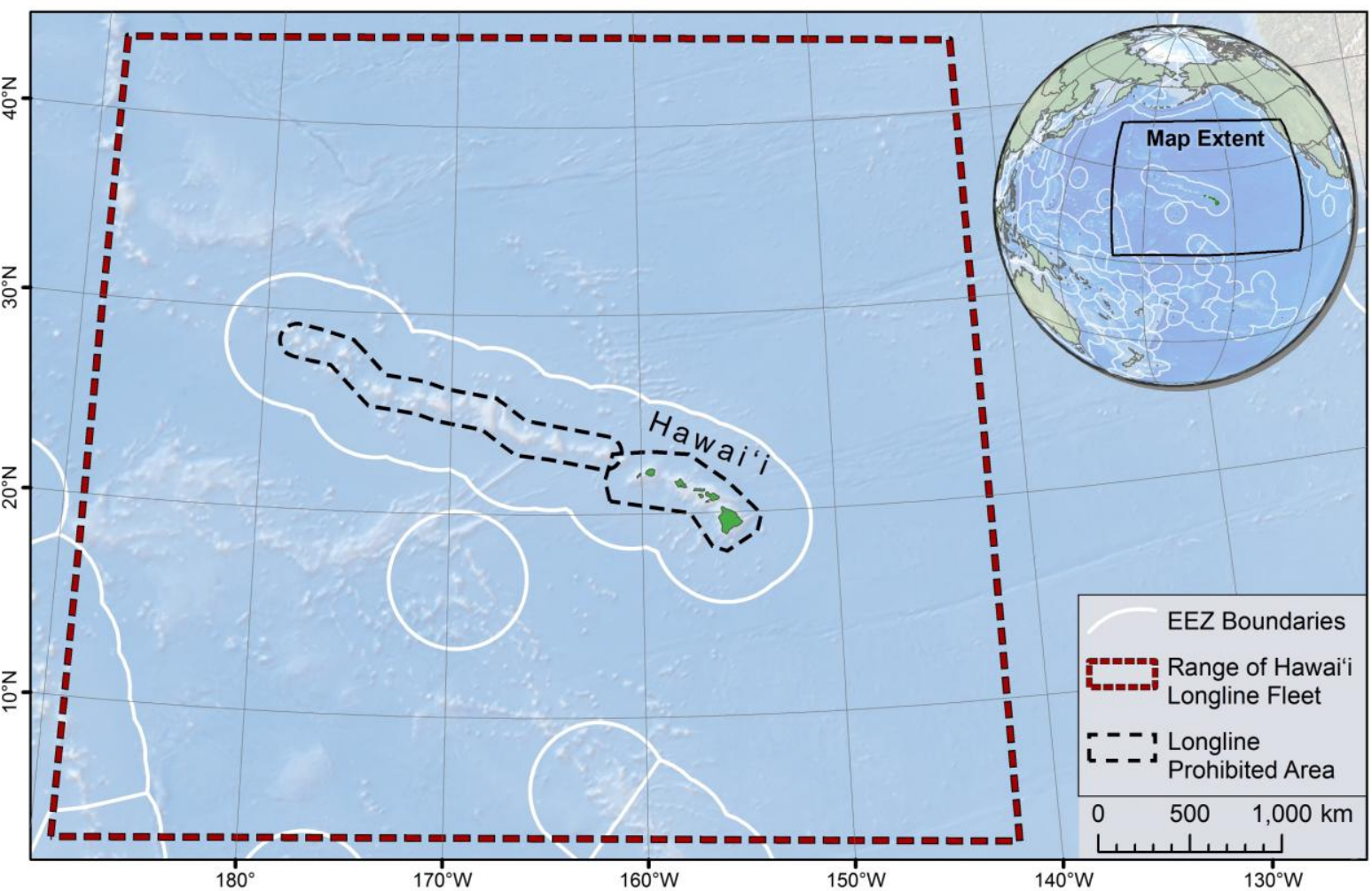




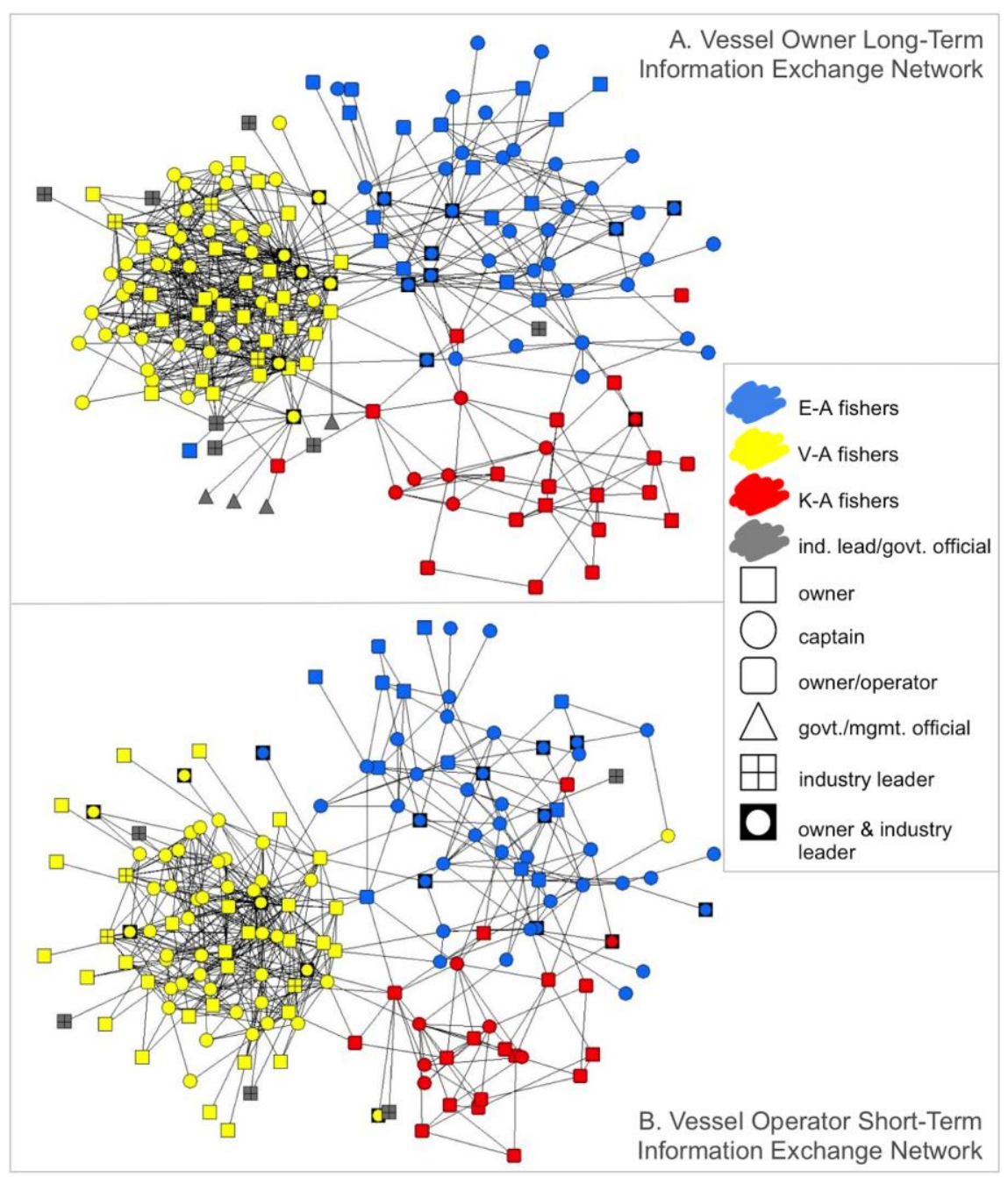


851 Table 1. Description of input, vessel, and owner and operator specific variables.

\begin{tabular}{|c|c|}
\hline Variable & Description \\
\hline \multicolumn{2}{|l|}{ Capital and labor } \\
\hline Trip days & Total trip length (in days), including days spent on travel \\
\hline Crew size & Number of persons on the boat, including the operator \\
\hline Fixed cost & $\begin{array}{l}\text { Annual fixed operating costs }(\$ / y r) \text {, including dry dock, engine work, } \\
\text { technology upgrades, and continuous maintenance }\end{array}$ \\
\hline Variable cost & $\begin{array}{l}\text { Annual variable operating costs }(\$ / y r) \text {, i.e., total annual trip-level costs, } \\
\text { including fuel, bait, ice, and other miscellaneous items (used in vessel } \\
\text { owner analysis) }\end{array}$ \\
\hline Other input & $\begin{array}{l}\text { Trip-level variable operating costs ( } \$ \text { /trip), including fuel, bait, ice, and } \\
\text { other miscellaneous items (used in vessel operator analysis) }\end{array}$ \\
\hline \multicolumn{2}{|l|}{ Human capital } \\
\hline Education & $\begin{array}{l}\text { Value } 1 \text { if the owner or operator had some college education, } 0 \\
\text { otherwise }\end{array}$ \\
\hline Experience & Owner or operator's fishing experience (years) \\
\hline \multicolumn{2}{|c|}{ Information exchange variables } \\
\hline \multicolumn{2}{|l|}{ Network prominence } \\
\hline Centrality (indegree) & $\begin{array}{l}\text { Number of incoming ties identified as important for exchanging long-run } \\
\text { information (owners); number of incoming ties identified as important } \\
\text { for exchanging short-run information (operators) }\end{array}$ \\
\hline \multicolumn{2}{|l|}{ Brokerage } \\
\hline Efficiency & $\begin{array}{l}\text { A measure of an optimized network that idealizes non-redundant } \\
\text { contacts. Calculated for owners using the long-run information } \\
\text { exchange network, and operators using the short-run information } \\
\text { exchange network (see section 3.4) }\end{array}$ \\
\hline Inter-ethnic ties & $\begin{array}{l}\text { Total number of inter-ethnic ties in the long-run information exchange } \\
\text { network (owners); total number of inter-ethnic ties in the short-run } \\
\text { information exchange network (operators) }\end{array}$ \\
\hline
\end{tabular}

\section{Vessel specific variables}

Target: swordfish

Vessel age

Vessel size: small

Vessel size: medium
Value 1 if the vessel targeted swordfish for at least 1 trip in 2012, 0 otherwise (targeted tuna only)

Age of vessel as of 2013

Value 1 if the vessel is a small size ( $\leq 55$ feet), 0 otherwise

Value 1 if the vessel is a medium size ( $>55$ feet and $<74$ feet), 0 otherwise

Value 1 if the vessel was owner-operated, 0 otherwise (hired captain)

Value 1 if the owner/operator is Euro-American, 0 otherwise

Value 1 if the owner/operator is Korean-American, 0 otherwise 
854 Table 2. Summary statistics for variables in vessel owner's annual-level production function, 2012 ( $n$ $855=91$ fishing vessels).

\begin{tabular}{lccc}
\hline Variable & Unit & Mean & Std. dev \\
\hline Output (annual revenue) & USD & $\$ 758,062.30$ & $\$ 275,751.80$ \\
Capital and labor & & & \\
Trip days & days/yr & 254.703 & 210.991 \\
Crew size & no. of persons & 5.810 & 0.710 \\
Fixed cost & $\$ / y r$ & $\$ 98,734.49$ & $\$ 36,845.37$ \\
Variable cost & $\$ / y r$ & $\$ 343,420.10$ & $\$ 102,752.60$
\end{tabular}

Human capital

Education

some college or above $=1$

0.495

0.503

Experience years fishing

27.962

12.215

\begin{tabular}{|c|c|c|c|}
\hline \multicolumn{4}{|c|}{ Information exchange variables (long-term) } \\
\hline \multicolumn{4}{|c|}{ Network prominence } \\
\hline Centrality (indegree) & no. of incoming ties & 12.044 & 14.705 \\
\hline \multicolumn{4}{|l|}{ Brokerage } \\
\hline Efficiency & $\begin{array}{l}\text { no. of non-redundant contacts/ } \\
\text { total no. of contacts }\end{array}$ & 0.836 & 0.091 \\
\hline Inter-ethnic ties & no. of inter-ethnic ties & 1.802 & 2.177 \\
\hline \multicolumn{4}{|l|}{ Vessel specific variables } \\
\hline Target: swordfish & yes $=1$ & 0.154 & 0.363 \\
\hline Vessel age & years & 27.846 & 10.421 \\
\hline Vessel size: small & yes $=1$ & 0.099 & 0.3 \\
\hline Vessel size: medium & yes $=1$ & 0.44 & 0.499 \\
\hline \multicolumn{4}{|l|}{ Owner specific variables } \\
\hline Owner-operated & yes $=1$ & 0.352 & 0.48 \\
\hline Ethnicity: Euro-American & yes $=1$ & 0.374 & 0.486 \\
\hline Ethnicity: Korean-American & yes $=1$ & 0.165 & 0.373 \\
\hline
\end{tabular}


858 Table 3. Summary statistics for variables included in vessel operator's trip-level production function, $8592012(n=853$ tuna fishing trips).

\begin{tabular}{lccc}
\hline Variable & Unit & Mean & Std. dev \\
\hline Output (trip revenue) & USD & $\$ 67,739.81$ & $\$ 33,606.92$ \\
& & & \\
Capital and labor & & & \\
Trip days & days/trip & 22.535 & 5.408 \\
Crew size & no. of persons & 4.682 & 0.672 \\
Other input & \$/trip & $\$ 29,683.97$ & $\$ 8,797.28$
\end{tabular}

Human capital

Education

some college or above $=1$

0.258

0.438

Experience

years fishing

24.759

9.218

Information exchange variables (short-term)

Network prominence

Centrality (indegree)

no. of incoming ties

4.026

4.455

Brokerage

Efficiency

Inter-ethnic ties no. of non-redundant contacts/ total no. of contacts

no. of inter-ethnic ties

$\begin{array}{ccc}\text { years } & 26.498 & 10.113 \\ \text { yes }=1 & 0.134 & 0.341 \\ \text { yes }=1 & 0.406 & 0.491\end{array}$

Owner specific variables

Owner-operated

Ethnicity: Euro-American

Ethnicity: Korean-American

$\begin{array}{lll}\text { yes }=1 & 0.328 & 0.470 \\ \text { yes }=1 & 0.409 & 0.492 \\ \text { yes }=1 & 0.196 & 0.397\end{array}$

Vessel specific variables

Vessel age

yes $=1$

0.789

0.131

0.584

0.93

861

862 
863 Table 4. Correlation coefficients among information exchange metrics

\begin{tabular}{|c|c|c|c|c|c|c|c|}
\hline & \multicolumn{3}{|c|}{$\begin{array}{c}\text { Vessel Owners } \\
\text { (long-term network) }\end{array}$} & \multicolumn{3}{|c|}{$\begin{array}{l}\text { Vessel Operators } \\
\text { (short-term network) }\end{array}$} \\
\hline & & 1 & 2 & 3 & 1 & 2 & 3 \\
\hline 1 & $\begin{array}{l}\text { Centrality } \\
\text { (indegree) }\end{array}$ & 1 & & & 1 & & \\
\hline 2 & Efficiency & 0.214 & 1 & & -0.123 & 1 & \\
\hline 3 & Inter-ethnic ties & 0.628 & 0.563 & 1 & 0.203 & 0.277 & 1 \\
\hline
\end{tabular}

864

865 
866 Table 5. The role of information exchange on fisher productivity.

\begin{tabular}{|c|c|c|c|c|c|}
\hline & \multirow[b]{2}{*}{ unit } & \multicolumn{2}{|c|}{$\begin{array}{l}\text { Owner long-run model } \\
\text { (annual; } n=91 \text { vessels) }\end{array}$} & \multicolumn{2}{|c|}{$\begin{array}{l}\text { Operator short-run model } \\
\text { (trip-level; } n=853 \text { trips) }\end{array}$} \\
\hline & & Coef & SE & Coef & SE \\
\hline \multicolumn{6}{|l|}{ Capital and labor } \\
\hline Trip days & $\log$ & $0.821^{* * *}$ & 0.249 & $0.767^{* * *}$ & 0.279 \\
\hline Crew size & $\log$ & 0.260 & 0.266 & 0.083 & 0.180 \\
\hline Fixed cost (annual only) & $\log$ & 0.101 & 0.088 & & \\
\hline Variable cost (annual only) & $\log$ & 0.299 & 0.204 & & \\
\hline Other input (trip-level only) & $\log$ & & & $0.610^{* * *}$ & 0.197 \\
\hline \multicolumn{6}{|l|}{ Human capital } \\
\hline Education & yes $=1$ & -0.092 & 0.069 & $-0.109^{*}$ & 0.058 \\
\hline Experience & $\log$ & 0.003 & 0.003 & 0.004 & 0.003 \\
\hline
\end{tabular}

\section{Information exchange variables \\ Network prominence}

Centrality (indegree)

Brokerage

Efficiency

Inter-ethnic ties

$\begin{array}{lcccc}\log & 0.085^{\star *} & 0.037 & 0.050^{*} & 0.026 \\ & & & & \\ \log & -0.443^{*} & 0.235 & -0.265^{\star * *} & 0.100 \\ \log & ++ & ++ & -0.202^{* * *} & 0.079\end{array}$

Vessel specific variables

Target: swordfish (annual only) yes $=1$

Vessel age

level

$-0.143^{*}$

0.075

Vessel size: small

Vessel size: medium

yes $=1$

$-0.006^{\star *}$

0.003

$-0.007^{* * *}$

0.003

$-0.154$

0.127

0.016

0.114

yes $=1 \quad-0.026$

0.070

$0.167^{\star \star *}$

0.054

Owner specific variables

Owner-operated

$$
\text { yes }=1
$$

$-0.059$

0.062

0.030

0.050

Ethnicity: Euro-American

yes $=1$

$0.163^{*}$

0.096

$0.283^{\star * \star}$

0.057

Ethnicity: Korean-American

yes $=1$

$-0.086$

0.113

$-0.063$

0.077

Constant

level

$3.450^{\star *}$

1.511

$-2.054$

1.405

$\mathrm{R}^{2}$

0.802

0.338

Adj. $R^{2}$

0.762

0.327

${ }^{\star},{ }^{\star *},{ }^{\star \star \star}$ denotes significance at the $0.10,0.05$, and 0.01 level. Standard errors were bootstrapped using 1,000

868 random samples.

$869{ }^{++}$Omitted due to collinearity (see Table 4). 